\title{
An Educational Framework for Digital Manufacturing in Schools
}

\author{
Glen Bull, ${ }^{1,2}$ Hossein Haj-Hariri, ${ }^{3}$ Rosa Atkins, ${ }^{4}$ and Pam Moran ${ }^{5}$
}

\begin{abstract}
The Laboratory School for Advanced Manufacturing (Lab School) was established to identify and develop effective educational practices for advanced manufacturing technologies in schools. The Lab School is grounded in the premise that students can learn through the design and fabrication process. Students of all ability levels from a diverse population participate in the program with the goal of increased diversity in the STEM pipeline. The advent of digital fabrication technologies such as desktop 3D printers now offers students an opportunity to see their ideas and concepts realized in physical form. This capability offers an opportunity to reconsider the curriculum and re-establish vital interconnections among the historically related subjects. For example, Invention Kits designed and fabricated in engineering classes are being used to advance learning through related experiments in science classes. Achieving these benefits requires careful planning. Factors that must be addressed include both pedagogical elements such as alignment with instructional objectives, and industrial processes that include sourcing of materials, workflow, and scheduling. These activities may encourage an interest in engineering as a career for some students. Other students will master related skills that will facilitate their work in other fields and support interests related to personal fulfillment in areas such as the arts.
\end{abstract}

\section{Introduction and Background}

THE CURRENT MODEL of public education evolved during the industrial revolution. The compartmentalization into subjects and the structuring of curricula have provided an efficient means of educating large numbers of students. While fully acknowledging the good of public education, we note a sense that, over the years, the natural and historic interconnection of subjects such as mathematics, physical sciences, and philosophy has become more opaque. Each should act as context and motivation for the others. For instance, calculus was invented to facilitate the study of dynamics and celestial mechanics, not to torment generations of students who are presented the subject out of context.

'Department of Curriculum \& Instruction, Curry School of Education, University of Virginia, Charlottesville,

Virginia.

¿Laboratory School for Advanced Manufacturing, Charlottesville, Virginia.

${ }^{3}$ Department of Mechanical and Aerospace Engineering and K-12 Engineering Design Laboratory, School of Engineering and Applied Science, University of Virginia, Charlottesville, Virginia.

${ }^{4}$ Charlottesville City Schools, Charlottesville, Virginia.

${ }^{5}$ Albemarle County Public Schools, Charlottesville, Virginia.

(c) Glen Bull et al. 2015; Published by Mary Ann Liebert, Inc. This Open Access article is distributed under the terms of the Creative Commons Attribution Noncommercial License (http://creativecommons.org/licenses /by-nc/4.0/) which permits any noncommercial use, distribution, and reproduction in any medium, provided the original author(s) and the source are credited.

The advent of 3D printing and advanced manufacturing provides the opportunity to re-establish the vital interconnection among the historically related subjects. Once learned in the proper and natural context, the knowledge will be more readily retained. ${ }^{1}$ Achieving this necessary contextualization is more intricate than simply purchasing a 3D printer and placing it in the classroom, however. ${ }^{2}$ 


\section{Laboratory Schools}

In 1896, John Dewey established a school designed to serve as a laboratory for development of effective practices. This laboratory school was founded in a collaboration between the University of Chicago and local educators, students, and parents. Since that time, approximately two dozen laboratory schools have been established across the nation.

In 2013, a Laboratory School for Advanced Manufacturing (Lab School) was established to develop effective educational practices for advanced manufacturing technologies in schools. The Lab School is a joint venture by the University of Virginia's Curry School of Education and School of Engineering and Applied Science in collaboration with the Charlottesville City Schools and the Albemarle County Public Schools. ${ }^{3}$ The Lab School consists of three sites linked via videoconferencing: (1) the Buford Engineering Design Academy in Charlottesville, (2) the Sutherland Engineering Design Academy in Albemarle County, and (3) a complementary K-12 Engineering Design Laboratory established to support this effort in the School of Engineering and Applied Science at the University of Virginia.

The mission of the Lab School is to pilot and validate instructional resources and activities that can be shared with other schools. Resources developed in this manner are released in an open-source format that can be adapted by any other educational institution for noncommercial use.

\section{Instructional Framework}

The goal of the Lab School is to provide context for the existing curricula, and to identify and develop effective educational practices for advanced manufacturing technologies in schools. The introduction of principles and tools of advanced manufacturing in the schools can serve to introduce all students to the fields of manufacturing and engineering. ${ }^{4}$ This can encourage students to pursue careers in those fields who otherwise might not have this opportunity.
However, that is not our primary objective. The foremost goal, as noted above, is pedagogical. The outcomes we strive for include imparting the qualities of numeracy, collaboration, and problem solving, as well as appreciation for scale and estimation, and an ability to visualize in three dimensions. These outcomes will help the students be better at whatever they choose to do while simultaneously allowing them to become better informed citizens.

Young students now have the opportunity to see their ideas and concepts realized in physical form. ${ }^{5}$ The Lab School maxim, Make to Learn, is grounded in the premise that students can learn through the design and fabrication process. A series of guiding questions provides an interdisciplinary framework for the Lab School. This framework is adapted from a course, Engineering in the Modern World, developed by Michael Littman and David Billington at Princeton. ${ }^{6}$ The adapted framework incorporates the following questions considered in science, engineering, and history classes:

- Scientists analyze, asking, "How does it work?"

- Engineers invent, asking, "What is it good for?"

- Historians reflect, asking, "What is the impact?"
These guiding questions motivate a cycle of "Discover, Make, Learn" that takes place across science, engineering, and history classes, respectively. The process is not linear. Students in engineering class may reconstruct an invention such as the Charles Page "electromagnetic engine" patented in 1854 that is subsequently used for experiments in science classes. In history classes, students then retrospectively study patterns of innovation to understand the way in which this process occurs and its impact on the world at large. An understanding of this process can inform ways in which future innovations are adopted and facilitate students' development of their own innovations after they master foundational skills (Fig. 1).

The Lab School is not a magnet school. Students of all ability levels from a diverse population participate in the program. A key principle is that all students have the opportunity to participate in related activities across a range of classes and subject areas.

This work is undertaken in collaboration with a coalition of corporate and nonprofit partners. The Lab School benefits from consultation and resources from the Fab@School coalition. This coalition also provides a mechanism for dissemination of content and resources developed and piloted within the Lab School.

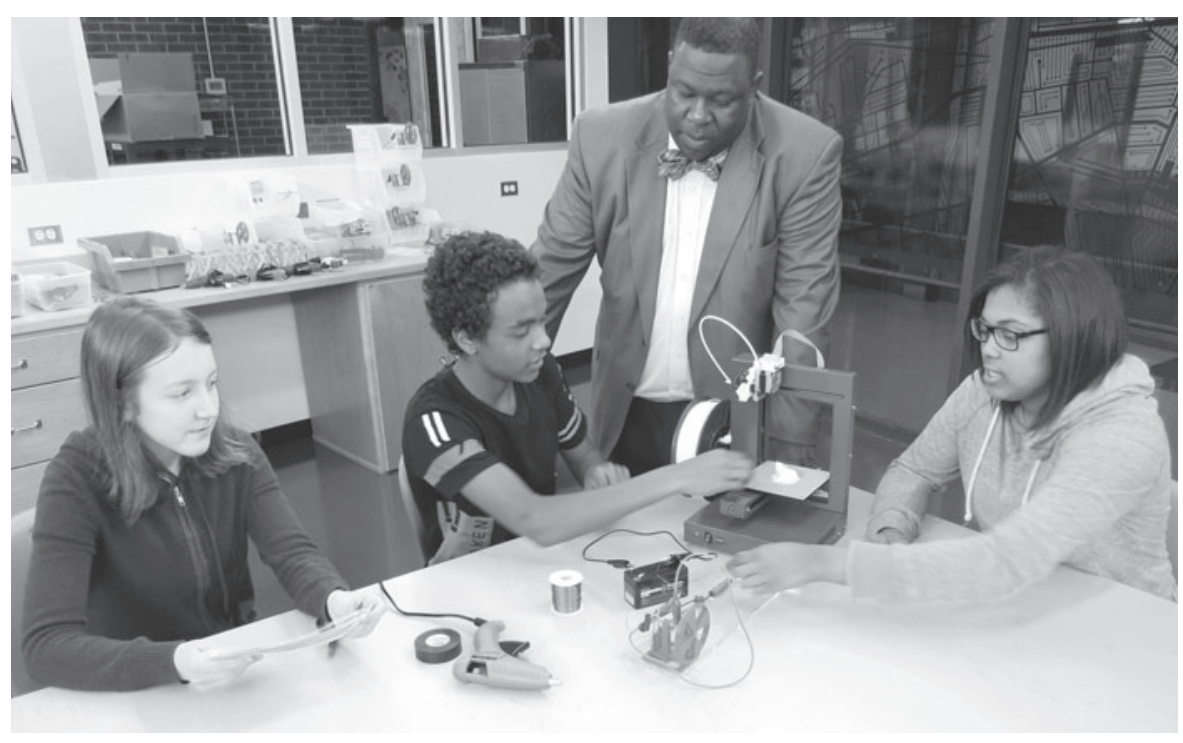

Figure 1. Lab School engineering students work on development of an instructional kit to support experiments in a related physical science class. 


\section{Establishing a Digital Manufacturing Program}

Establishing a digital manufacturing program in a K-12 school adds additional complexity in areas in which few teachers or administrators currently have prior preparation. Both industrial processes and pedagogical elements must be considered. Establishing an effective program requires additional planning both by building leaders and in the central office.

The Lab School receives several inquiries each week seeking information about use of $3 \mathrm{D}$ printers in schools. A number of educational leaders also visit the school each year. Most inquiries relate to ways of financing, acquiring, and maintaining equipment.

However, critical elements for success include construction of school schedules to facilitate access and time as well as professional development for teachers to learn how to manage the technologies, whose effective use requires alignment with curricular goals and instructional standards. Factors to consider include the types of technologies, location within the school, coordination across disciplines, professional development for teachers, and assessment.

\section{Acquisition of Technology}

A well-designed school fabrication laboratory should include a range of digital fabrication technologies, including computer-controlled die cutters, digital milling machines, laser cutters, and other technologies. Each has its own role and use. ${ }^{7}$ An effective plan for a school system incorporates an appropriate mix of these tools (Table 1).

Most objects of any complexity produced with a 3D printer take several hours to print, and typically cannot be designed and produced in the same class period. In contrast, a digital die cutter is inexpensive, and can be acquired for as little as $\$ 100$. It can be used with inexpensive materials such as card stock, and typically can fabricate an object in a minute or two. These characteristics affect the logistics of classroom planning.

Table 1. Selected digital fabrication tools

\begin{tabular}{|l|r|l|l|}
\hline Fabricator & Price & Material & Speed \\
\hline Digital die cutter & $\$ 100$ & Cardstock and vinyl & Fast \\
3D printer & $\$ 1000$ & ABS or PLA plastic & Slow \\
Digital milling & $\$ 1000$ & Wood or plastic & Slow \\
machine & $\$ 10,000$ & Wood or acrylic & Fast \\
Laser cutter & & & \\
\hline
\end{tabular}

Table 2. Characteristics of digital fabrication tools

\begin{tabular}{|c|c|c|c|c|}
\hline Fabrication tool & $\begin{array}{l}\text { Acquisition } \\
\text { cost }\end{array}$ & $\begin{array}{l}\text { Operation } \\
\text { cost }\end{array}$ & $\begin{array}{l}\text { Speed of } \\
\text { operation }\end{array}$ & $\begin{array}{l}\text { Durability of } \\
\text { product }\end{array}$ \\
\hline Digital die cutter & Low & Low & Fast & Fragile \\
\hline 3D printer & Moderate & Moderate & Slow & Durable \\
\hline Digital milling machine & Moderate & Moderate & Slow & Durable \\
\hline Laser cutter & High & Low & Fast & Durable \\
\hline
\end{tabular}

The function of each digital fabrication tool can be summarized with respect to four parameters: (1) acquisition cost, (2) operation cost, (3) speed of operation, and (4) durability of product (Table 2). Digital die cutters are inexpensive and safe to use in elementary classrooms, and can scaffold use of more complex fabrication systems in later grades.

After a prototyped design is perfected in industry, processes such as injection molding are used to manufacture the object quickly and inexpensively in large quantities. Similarly, if an item is needed in large quantities in a school, manufacturing technologies such as resin-based casting should be considered.

The hardware used in the Lab School has evolved as the technology has advanced. In work that first led to its establishment, the Fab@School 3D printer was developed through a collaborative project directed by Hod Lipson at the Cornell College of Engineering. This consisted of an open-source kit that could be assembled for less than $\$ 1,000$ in parts. As desktop 3D printers became more affordable, a mix of $3 \mathrm{D}$ printers such as the Makerbot Replicator (Stratasys, Eden Prairie, MN) and the Afinia Model 480H (Afinia, Chanhassen, $\mathrm{MN}$ ) was acquired. These technologies were supplemented with digital die cutters such as the Silhouette Portrait (Silhouette America, Lehi, UT) and laser cutters such as the Universal VLS series (Universal Laser Systems, Scottsdale, AZ). The specific models and mix of hardware will continue to change as the technology advances.

Computer-assisted design (CAD) software plays a crucial role. Industrial CAD applications are developed as design tools rather than design learning tools. The Lab School has collaborated in development of a CAD program for schools, Fab@School Maker Studio (FableVision, Boston, MA). This program includes features specifically designed to support instructional objectives. It currently is the only CAD program that supports both inexpensive consumer products such as digital die cutters as well as more advanced equipment such as $3 \mathrm{D}$ printers. This feature allows students to rapidly develop and refine successive iterations of a prototype in inexpensive materials such as cardstock and vinyl, and then fabricate the final design in more permanent form using a $3 \mathrm{D}$ printer or laser cutter.

Maker Studio is designed for use in grades four through eight, allowing students to gain experience with the design and fabrication process at an early age (Fig. 2). Other programs such as Autodesk 123D Design and Solidworks $3 \mathrm{D}$ CAD software are then used as students gain more experience. 


\section{Placement of Technologies}

A key planning decision is the placement of the machines. Technologies that are relatively affordable, such as digital die cutters, can be placed in the classroom to allow students the experience of rapid prototyping in the context of their lessons. Technologies that are too expensive to place in a single classroom, such as laser cutters, can be placed in a central location. $3 \mathrm{D}$ printers and desktop CNC machines fall in between, and therefore may be placed directly in a classroom or in a central location, depending on the circumstances.

\section{Fabricating Physical Mechanisms for Instruction}

The Lab School uses digital manufacturing capabilities to fabricate physical mechanisms for instructional use. A joint project with the Smithsonian, American Innovations in an Age of Discovery: Teaching Science and Engineering Through Historical Reconstruction, selects inventions such as the telegraph, the telephone, and early electric motors to be digitized and made available on the Smithsonian X 3D website. $^{8}$ Web-based tools on the Smithsonian X 3D site allow students to inspect and analyze the inventions and fabricate reconstructed versions of the inventions using advanced manufacturing technologies (Fig. 3).

Lab School students use objects from the Smithsonian collections such as artifacts and 3D models, patent descriptions, and inventors' notebooks to reinterpret these key inventions and observe the scientific principles underpinning them. ${ }^{9}$ The Lab School science and engineering teachers collaborate to enable the students to address these challenges and enhance both disciplines.

This approach, termed historical scaffolding, is based on prior work in the Joseph Henry Center at Princeton. Lab School teachers collaborate to enable students to discover the connections between engineering and other subjects such as art, social studies, mathematics, technical writing, consumer science, and physical science. For instance, expertise

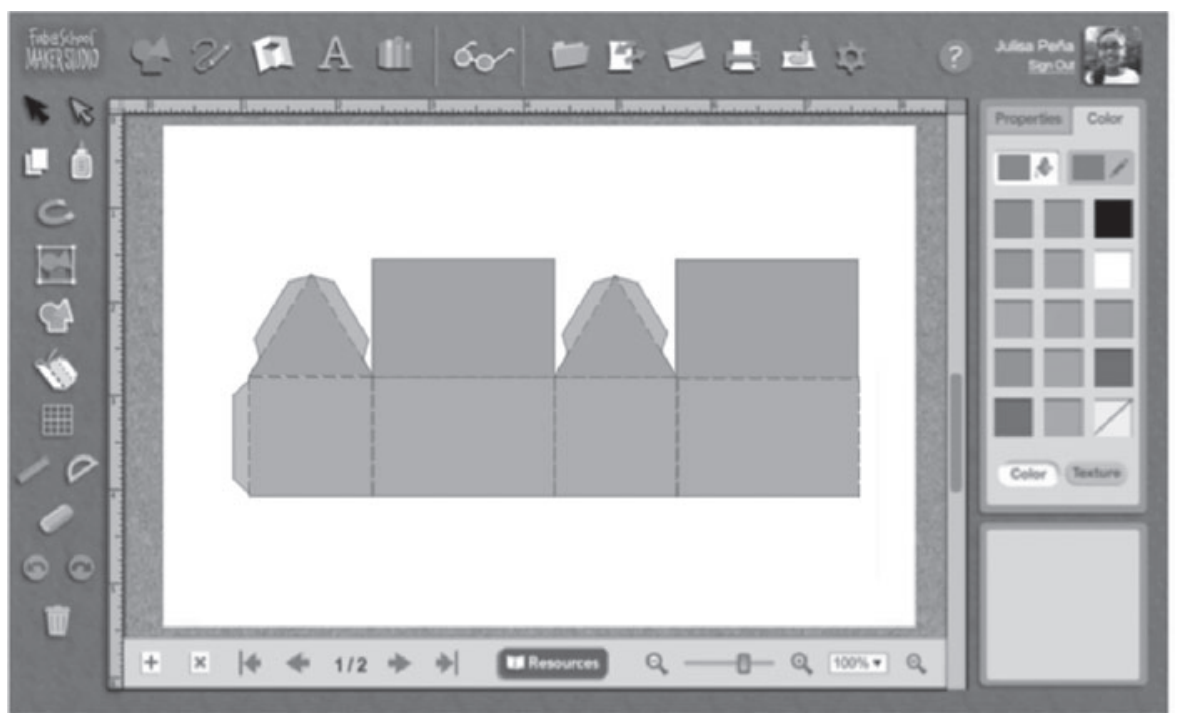

Figure 2. Maker Studio is designed for classroom use and can be used with a range of digital fabricators, including affordable digital die cutters and 3D printers.

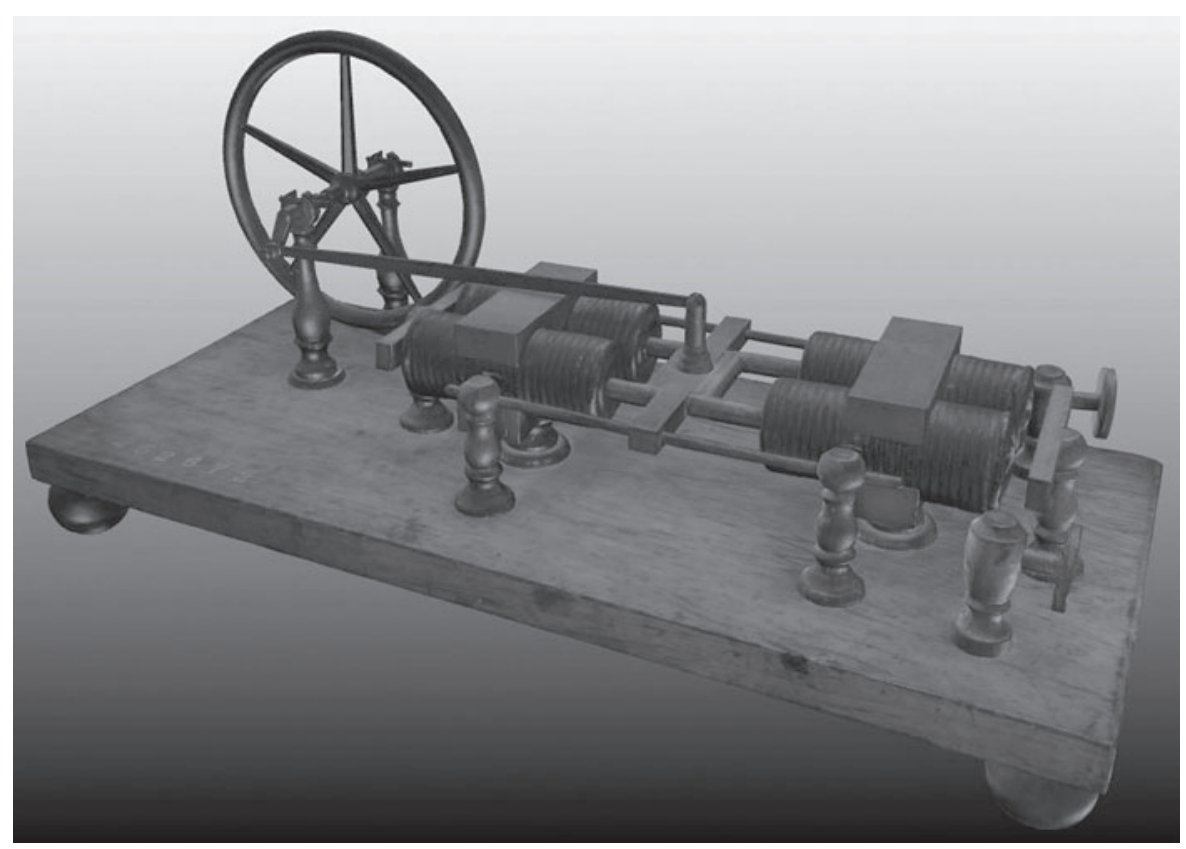

Figure 3. Digitized artifacts from the Smithsonian can be explored in three-dimensions online. In this example, the Charles Page electromagnetic engine patented in 1854 can be examined in detail from any perspective.

that students acquire in engineering class can be employed to scaffold development of kinetic sculptures and interactive murals in art class. The reinterpretation of the above inventions can support development of technical writing skills. Essentially, students will use engineering and mathematics or science in authentic contexts, and retain the concepts innately.

\section{Electric Motor Invention Kit}

An electromagnetic engine patented in 1854 by Charles Page is the basis of an initial Electric Motor Invention Kit (Fig. 4). Physical science classes in the Lab School previously used a demonstration motor purchased from a science supply house. A single demonstration motor was used in a 
lecture-style format at the front of the classroom. The ability to fabricate reconstructed versions of the Charles Page motor in engineering class makes it possible to shift to a project-based learning format ${ }^{10}$ in science class. Each team of three to four students can use the locally fabricated electric motor in a series of experiments in which students attempt to modify and improve the performance of the motor.

Use of an electric motor kit fabricated by a member of the science team who is also enrolled in an engineering elective offers several benefits. First, one member of the team will already be knowledgeable about the design and construction of the motor. Second, the enthusiasm of the engineering students for this activity may increase engagement and interest across the entire class. The engineering class has a mix of students of all ability levels. Some of the leaders in engineering class are students who are not academically gifted. Many of these students find themselves in a leadership role for the first time.

To achieve the above synergies, while respecting curricular goals of the schools, the objectives of the engineering and science classes must be aligned through the coordination of the schedules and pacing guides for the two classes. This additional complexity makes it possible to change the instructional method used in science class to a hands-on projectbased learning approach.

The invention kits are designed to address topics in the same amount of time that was previously allotted in the curricular pacing guide. This is accomplished by replacing multiple, separately taught experiences with a single integrated experience in the context of the invention (Table 3 ).

The reconstruction of the Charles Page electromagnetic engine is intended to be a reinterpretation of the design using digital manufacturing technologies rather than an exact duplication of the original (Fig. 5). This allows students to develop their own design using the same underlying principles. The Charles Page electric motor kit consists of three subassemblies: (1) a solenoid assembly

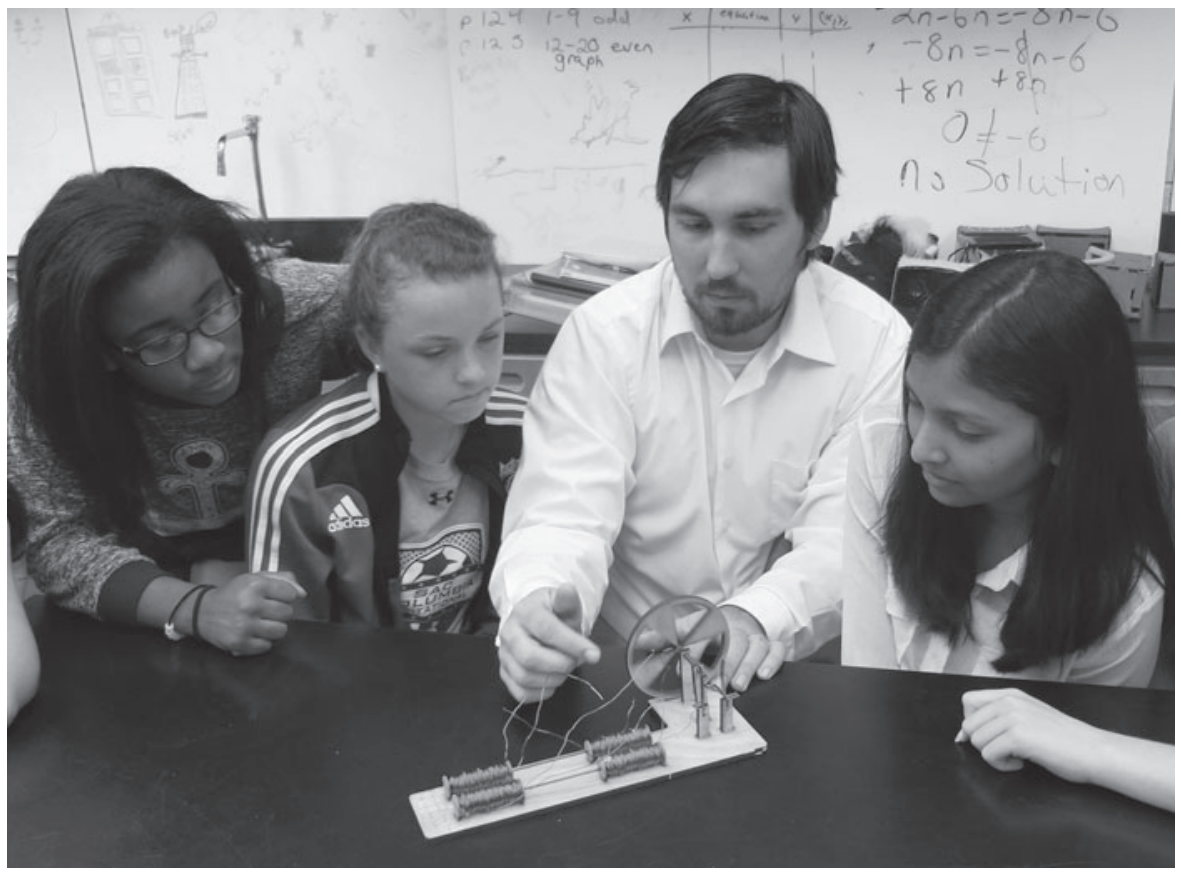

Figure 4. A Lab School science teacher uses Electric Motor Invention Kits to teach electricity and magnetism.

(consisting of solenoid winding tubes, an armature, and an armature pivot connector), (2) a commutator assembly (consisting of a flywheel, an axle with a bowed rotary contact, an axle sleeve bearing, and switching points), and (3) a connecting assembly (consisting of a crank and connecting linkage). The solenoid assembly drives the engine when powered by an electrical source. The commutator assembly provides a switching mechanism that alternately powers the left and right solenoids, moving the armature between the two solenoids. The connecting assembly links the solenoid assembly to the commutator and flywheel (Fig. 6).

This design allows a number of instructional standards for electricity and magnetism to be addressed. Challenges that students face during the process of reconstructing the engine include determination of the best adjustment of the phase and duty cycle of the commutator that achieves maximal speed of the motor with the least amount of current required for operation. Once the solenoid engine has been constructed in an engineering class, a series of experiments based on

\begin{tabular}{|c|c|}
\hline Covered & $\begin{array}{l}\text { Electricity and } \\
\text { magnetism topics } \\
\text { required by standards }\end{array}$ \\
\hline & a. Static electricity \\
\hline$\checkmark$ & b. Current electricity \\
\hline$\checkmark$ & c. Circuits \\
\hline$\checkmark$ & $\begin{array}{l}\text { d. Relationship between } \\
\text { electric current and } \\
\text { magnetic field }\end{array}$ \\
\hline$\checkmark$ & e. Electromagnets \\
\hline$\checkmark$ & f. Motors \\
\hline$\checkmark$ & g. Generators \\
\hline \multirow[t]{2}{*}{$\checkmark$} & h. Conductors \\
\hline & i. Semiconductors \\
\hline$\checkmark$ & j. Insulators \\
\hline
\end{tabular}

its use can be undertaken in a parallel science class.

The Charles Page motor uses a doubleacting solenoid and converts linear motion to rotary motion. The operation of the switching mechanism is readily 


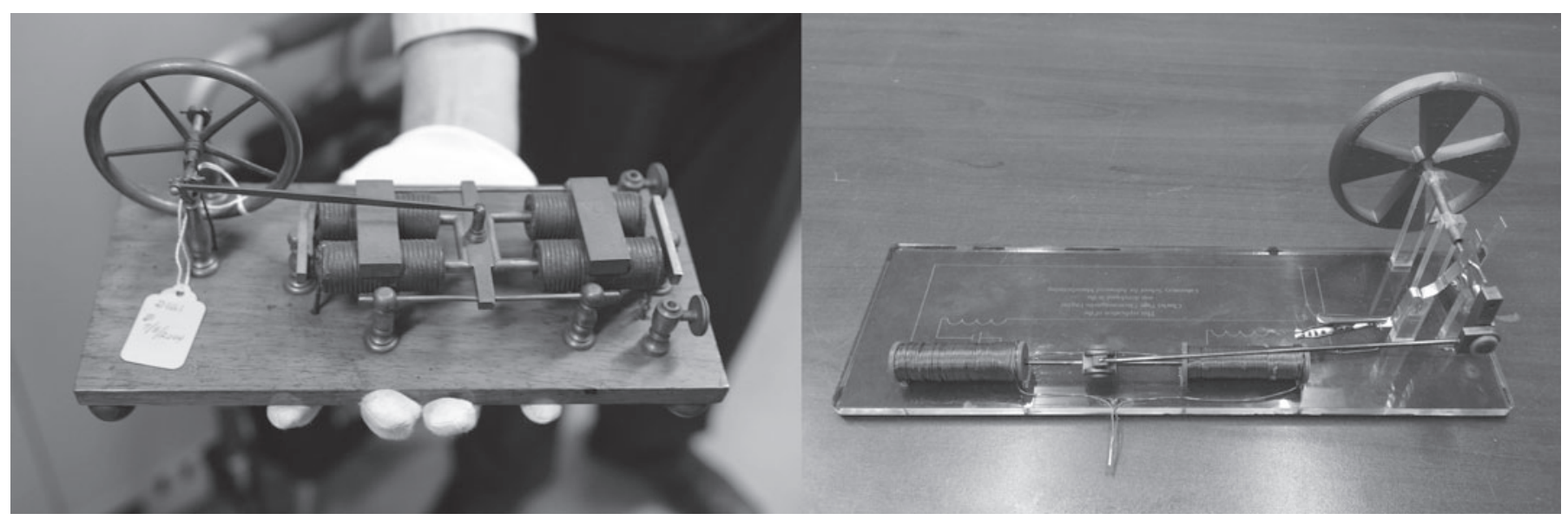

Figure 5. The original Charles Page patent model in the Smithsonian collections (left) and a historical reconstruction (right) fabricated with advanced manufacturing technologies.

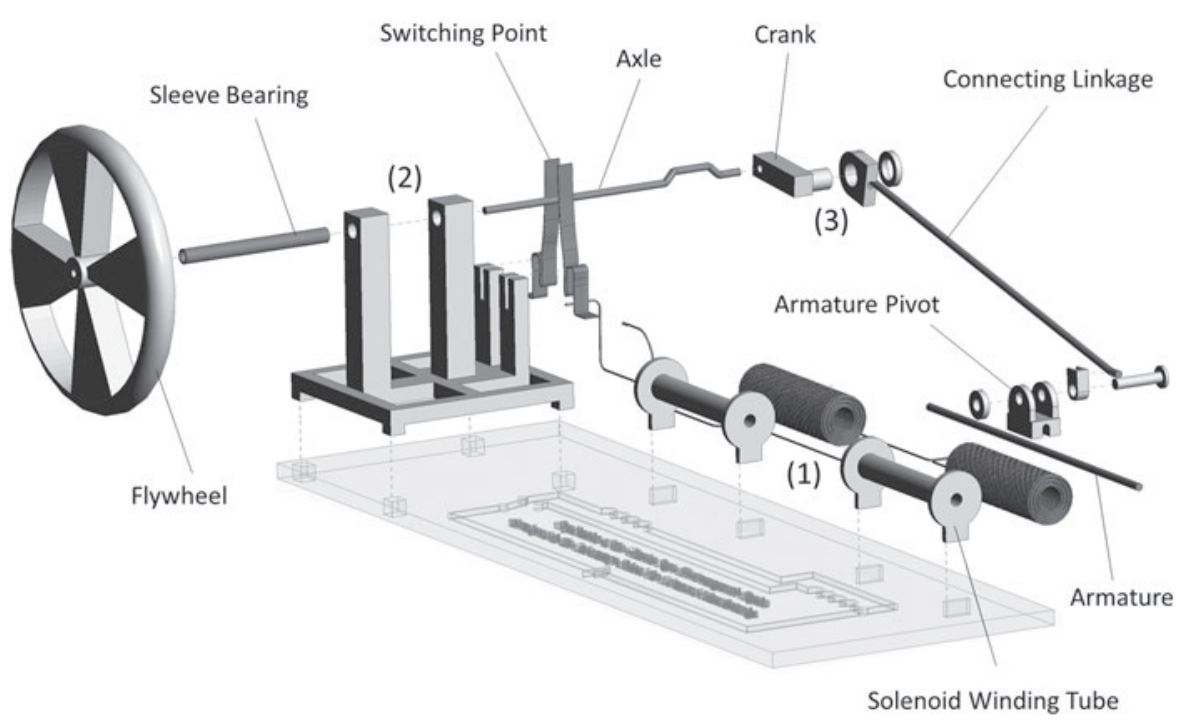

Figure 6. Elements of the reconstructed Charles Page electromagnetic engine.

observed and understood through the process of reconstructing it. The solenoid motor provides scaffolding for understanding the rotary motor designed by Davenport in 1837. Both motors can be used to power devices such as kinetic sculptures and mechanical toys (automata) designed by students, providing coverage of additional topics in physical science such as objectives related to force and motion.

\section{Coordination and Scheduling}

Establishing digital manufacturing processes in which an instructional apparatus designed and fabricated in one class (e.g., engineering) is used for instruction in another class (e.g., science) requires planning and coordination of both schedule and budget. The cost to print a single electric motor kit with a uPrint 3D printer (Stratasys) is approximately $\$ 30$ and takes 5 hours. The cost to create the same parts from a sheet of plywood using a laser cutter is less than a dollar and takes 15 minutes. Thus, a class set of 10 kits could take as many as 50 hours to print at a cost of $\$ 300$ or as little as 3 hours to fabricate at a cost of $\$ 10$ depending on the materials and fabricator used (Table 4).

In this application, the 3D printer has advantages for prototyping the design. However, once the design is finalized, the laser cutter is better suited to production of class sets both from the perspective of time and cost.

Resin-based casting is another option that may be suited to some applications. In this process, a silicone mold is made using a prototype of the object to be fabricated. Resin is then poured into

\section{Table 4. Time and materials cost for the electric motor kit}

\begin{tabular}{|l|l|c|c|l|c|}
\hline & Material used & Material cost (1) & Class set (10) & Fabrication time (1) & Class set (10) \\
\hline Stratasys uPrint & ABS plastic & $\$ 30$ & $\$ 300$ & 5 hours 15 min & 52 hours \\
Stratasys Makerbot & ABS plastic & $\$ 6$ & $\$ 60$ & 7 hours 30 min & 75 hours \\
Laser cutter & Acrylic & $\$ 3$ & $\$ 30$ & 0 hours 15 min & 3 hours \\
Laser cutter & Plywood & $\$ 1$ & $\$ 10$ & 0 hours 15 min & 3 hours \\
\hline
\end{tabular}




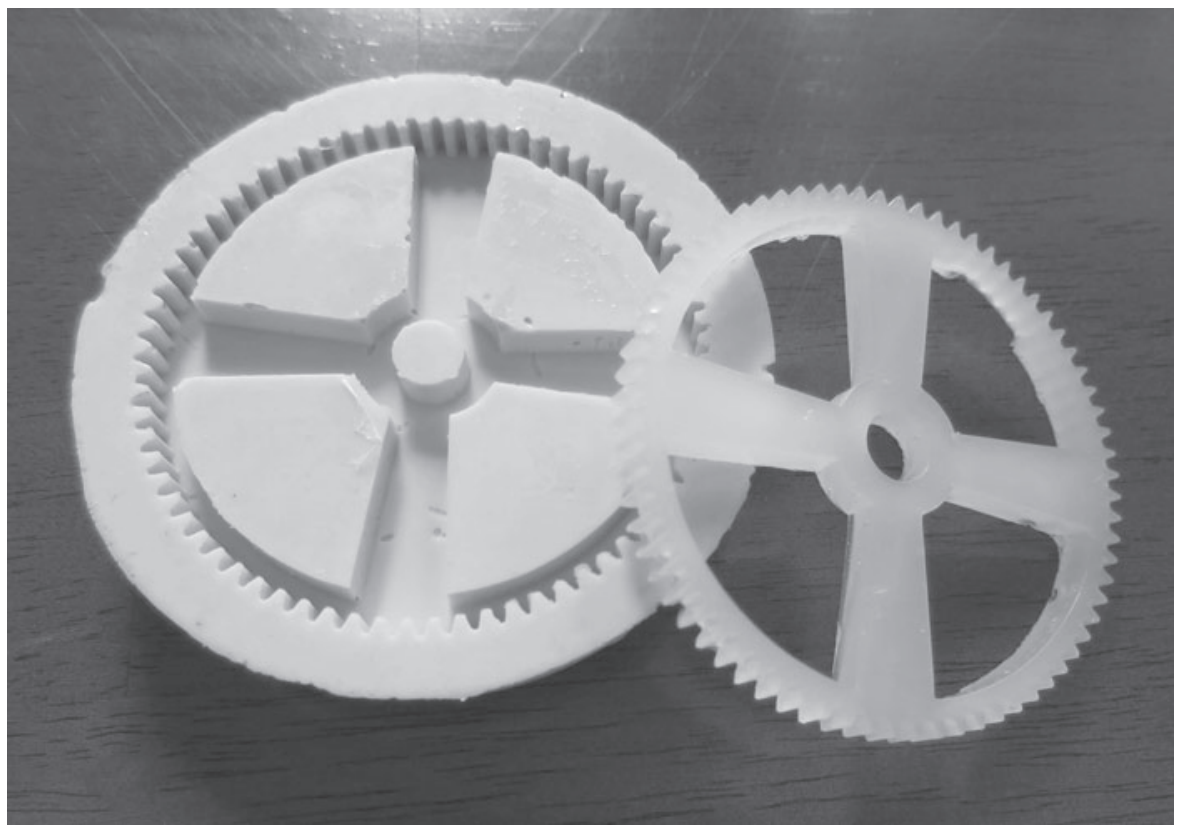

Figure 7. A resin-cast gear.

the mold to create a plastic part that is a duplicate of the original. This type of project can also be undertaken without advanced technology or digital fabrication equipment, making it a good starting point for schools with limited resources (Fig. 7).

Once the kits have been fabricated, the engineering teacher must determine the number of class periods that will be required to assemble the kits in time for use in experiments in science class. This coordination requires more planning by principals and building leaders as well as teachers. However, this planning makes an instructional activity feasible that would have been economically prohibitive without access to advanced manufacturing technologies.

In this instance, a solenoid engine kit aligned with science, engineering, and social studies instructional objectives previously was not commercially available at any price. Educators can now design and implement new instructional devices at the working interface where teaching occurs. Teachers and their students can become co-constructors of knowledge, harnessing a previously untapped resource.

\section{Conclusions}

Schools are rapidly acquiring digital fabrication technologies such as $3 \mathrm{D}$ printers. Adoption and use of digital manufacturing technologies can allow students to determine whether they enjoy the field of engineering, and to enter this field if their interest continues. Digital fabrication activities may spark an interest in engineering in general and a better understanding of what engineers do, demystifying engineering and helping students see themselves as capable of pursuing studies and careers in science and engineering.

Many other students will not adopt this as a professional career, but will find it fulfilling in their personal lives through activities ranging from design and fabrication of art and jewelry to hobbies such as robotics. They will also possess an elevated capacity for numeracy and spatial visualization, and have better appreciation for physical scales and their relative importance. The continuing expansion of the Maker Movement is evidence of ways in which these skills can be used for personal fulfillment in much the same way as other creative endeavors ranging from art to music currently can enhance an individual's life. This skill can lead to interests that will support on-going lifelong learning.

\section{Acknowledgments}

This material is based upon work supported by the National Science Foundation Grant No. 1030865-The FabLab Classroom: Preparing Students for the Next Industrial Revolution, and by additional support from the MacArthur Foundation, the Motorola Foundation, Cisco Foundation, the Noyce Foundation, the Alcoa Foundation, the Reynolds Center for Teaching, Learning \& Creativity, a Small Business and Innovation Research award, a U.S. Department of Education Investing in Innovation award, and through support from the Commonwealth of Virginia, the City of Charlottesville, and support from Canon USA, Afinia, FableVision, Microsoft, Northrup-Gruman, and private donors. Any opinions, findings, and conclusions or recommendations expressed in this material are those of the authors.

\section{Author Disclosure Statement}

No competing financial interests exist.

\section{References}

1. Bull G, Chiu J, Lipson H, et al. Advancing children's engineering through desktop manufacturing. In: Handbook of research on educational communications and technology. Springer, New York, NY, 2014; pp. 675688.

2. Lipson H, Kurman M. Fabricated: the new world of 3D printing. John Wiley and Sons, New York, NY, 2013.

3. Bull G, Haj-Hariri H, Nelson A. The lab in the classroom: $3 \mathrm{D}$ printers in schools. Make 2014;41:24-25.

4. Chiu J, Bull G, Berry RQ, et al. Teaching engineering design with digital fabrication: imagining, creating, and refining ideas. In: Emerging technologies for the classroom: a learning sciences perspective. Springer Science, New York, NY, 2012; pp. 47-62. 
5. Bull G, Groves J. The democratization of production. Learn Leading Technol 2009;37:36-37.

6. Billington DP, Billington DP Jr. Power, speed, and form: engineers and the making of the twentieth century. Princeton University Press, Princeton, NJ, 2006.

7. Bull G, Garofalo J. Technologies to support engineering education. In: The SAGE encyclopedia of educational technology. SAGE Publications, Thousand Oaks, CA, 2015; pp. 740-743.
8. Smithsonian Institution. American Innovations in an Age of Discovery. http://3d.si.edu/invention (last accessed June 11, 2015).

9. Bull G, Kotcho C, Hoffman M. The FabLab Classroom. Learn Leading Technol 2014;41:10-11.

10. Thomas JW, Mergendoller JR, Michaelson A. Project-based learning: a handbook for middle and high school teachers. The Buck Institute for Education, Novato, CA, 1999.
Address correspondence to:

Glen Bull

Curry School of Education at the University of Virginia

The Department of Curriculum, Instruction, and Special Education P.O. Box 400273

417 Emmet Street

Room 312 Bavaro Hall

Charlottesville, VA 22904-4273

E-mail: gbull@virginia.edu 